\title{
The Vibration Impact on the Surface Roughness Which are Made for Ck35 Steel During the Turning Process.
}

\author{
Latifi Ahmet $^{1}$, Abazi Arsim¹, Ibishi Ismet ${ }^{1}$, Shartari Astrit ${ }^{1}$ \\ ${ }^{1}$ University of Mitrovica "ISA BOLETINI"
}

\begin{abstract}
-ABSTRACT-
The vibrations have negative impact in the processing process by chip removal because they damage the quality of the processed surface, accelerate the cutting tool and machine wear; they can also lead to the cutting tool destruction or the parts of the machine and reduce the productivity of the cutting process.
\end{abstract}

Keywords: Vibrations, turning, machine, cutting tool etc.

\section{INTRODUCTION}

During the processing by chip removal appear some vibrations as consequence of force occurrences which have variable nature and which depend on the physical essence and the vibrations mechanisms. The Vibrations appearance, their amplitude, their amplitude and their frequency depend on the ratio between the vibrating forces and characteristics of the elastic system of the machine. The exciting forces can occur on the transmitting mechanism of the energy, on the cutting process, during the start or during the end of cutting. The vibrations have negative impact in the processing process by chip removal:

- $\quad$ Reduce the quality of the processed surface,

- Speed up the instrument wear and the machine,

- Can lead to destruction of the instrument or parts of the machine and,

- $\quad$ Reduce the cutting process productivity.

During the normal cutting appear some mandatory vibrations and self-excited.
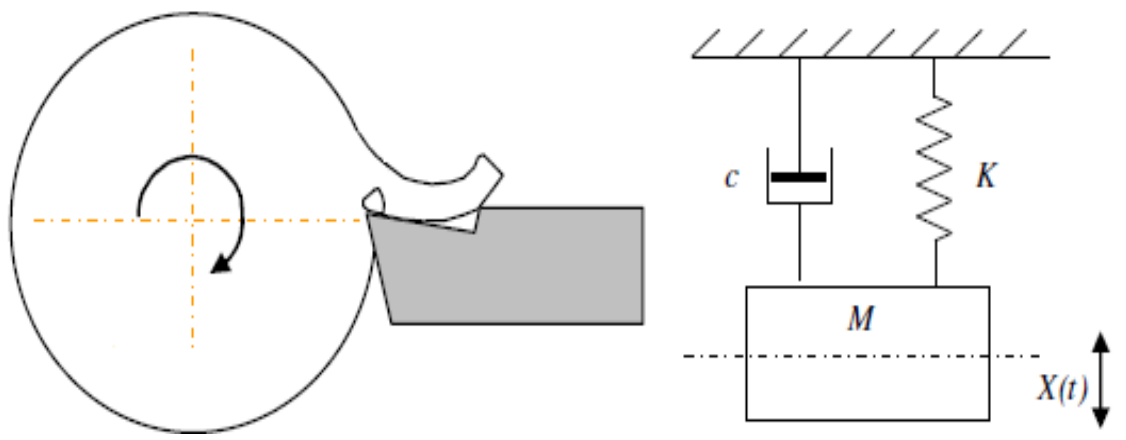

Fig. 1. The vibration system during the turning process

The Mandatory Vibrations - The mandatory vibrations at the machine tools appear due steady action of periodic forces. The mechanism character of creating periodic forces and mandatory vibrations can be variable. Mandatory vibrations at the detailed machine tool instrument can be caused:

- $\quad$ By self-system deficiencies

- $\quad$ By causes outside the system and

- $\quad$ By periodic replacement of chip section.

Self-excited Vibrations - Self-excited vibrations of the system machine-instrument detailed tool appear as an expression of certain internal instability in the system itself. The amplitude and the frequency of own vibrations depend on the settings of the elastic system. For the appearance of the own vibrations, it is necessary the initial impulse in the system which causes fluctuations at the cutting forces. At the analysis of self-excited vibrations, the detailed system and the system of the cutting instrument should be considered, which mutually differ in measures and stiffness, therefore also differ in frequencies. Based on this, there may be found three kinds of self-excited vibrations (figure 2): 

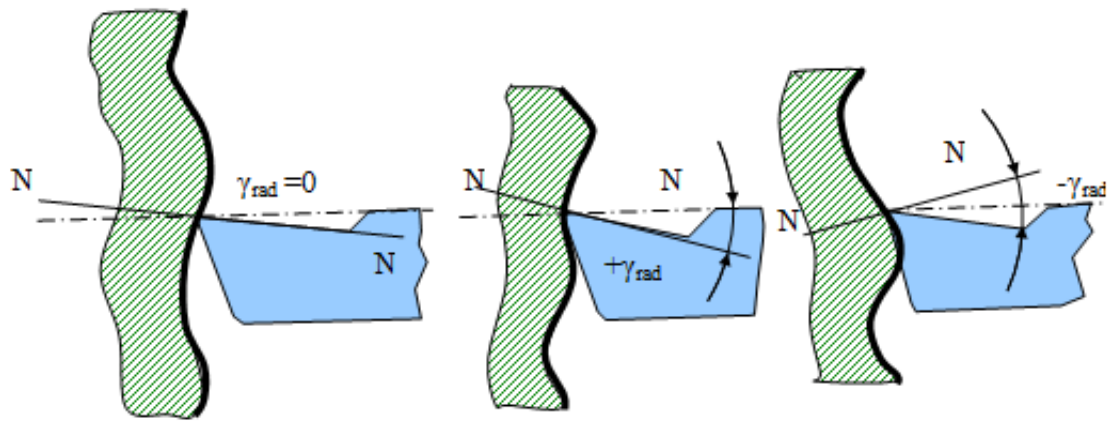

Fig.2 Change of the geometry of the cutting instrument due to radial vibrations
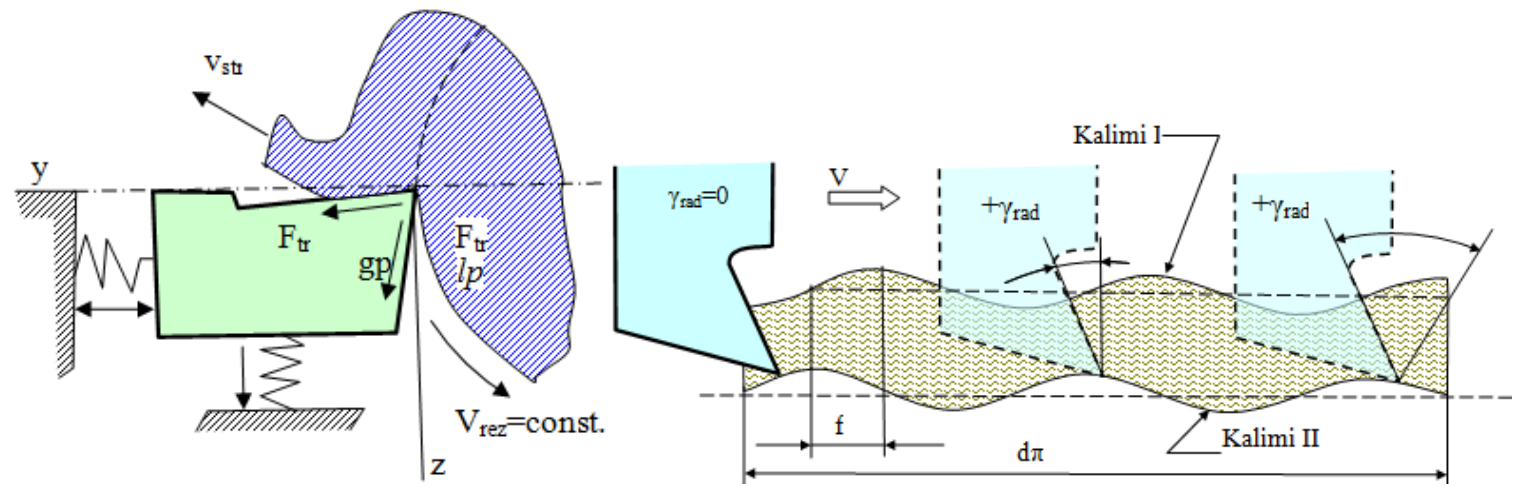

Fig. 3. a) Vibrations due to the change of the back surface, b) support (stimulation) of vibrations from the previous crossing route.

\section{CONDITIONS FOR CONDUCTING THE EXPERIMENT}

1. Choosing the material - Material which has been researched for measuring the parameters surface severity and of the vibrations is Ck 35 Steel, according to DIN's dimensions $\varnothing 55$ dhe $\mathrm{l}=550$.

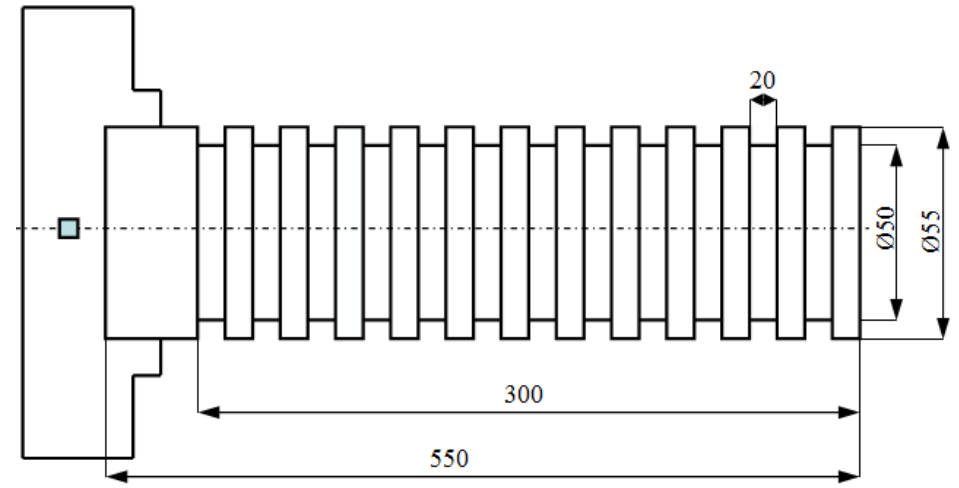

Fig. 4. The sample used in the experiment

2. Selecting the cutting tool - For the processing of the sample, it's used an cutting tool holder $90 \mathrm{~W} 20-\mathrm{T} 3 \mathrm{~K} 13$ according DIN's 3705, production of the German firm KNUTH, and one cutting insert ISO6-P10 production of Swedish firm Sandvik Coroman type TCMT 161308-MR 2025 following characteristics: $\alpha=45^{\circ}, \gamma=90^{\circ}, \beta=60^{\circ}$, $\mathrm{r}_{\varepsilon}=1.2[\mathrm{~mm}]$.
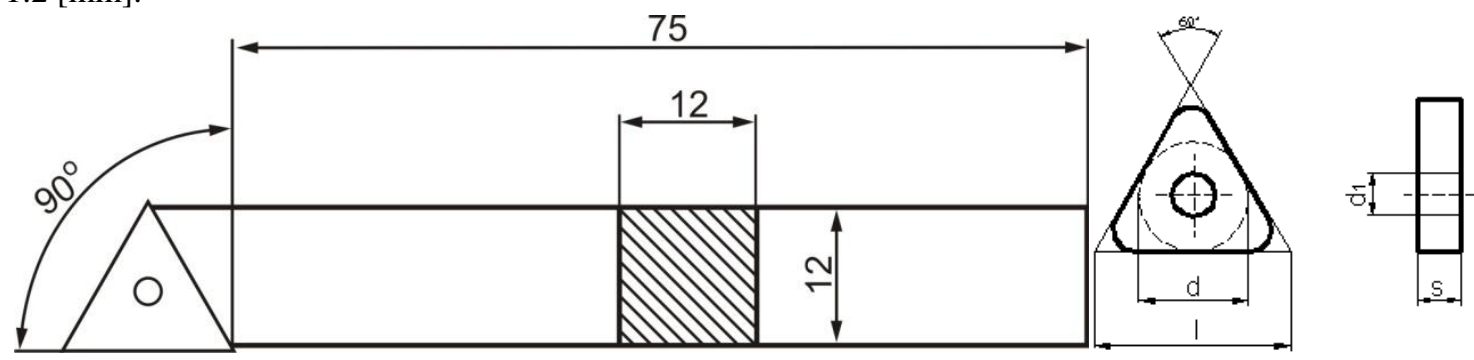

Fig. 5. Geometry of the cutting tool 
The Vibration Impact On The Surface Roughness Which Are Made For Ck35 Steel During The...

Selection of cutting regimes - Preparation of the sample is conducted in the turning machine by the selected cutting regime: cutting speed, cutting feet and the depth of cutting. Based on the number of the machine rotations, sample dimensions, consulted text, chemical compositions and mechanical properties, these spindle speeds (numbers) are acquired:

$n_{\max }=700 \mathrm{spin} / \mathrm{min}, n_{\text {ave }}=500 \mathrm{spin} / \mathrm{min}, n_{\min }=300 \mathrm{spin} / \mathrm{min}$.

For the sample preparation is used an experiment using three orthogonal factors with a measurement point plan and on the repeating on point zero four times $\left(2^{3}+4\right)$.

Tab. 1. Characteristics of cutting regimes and used code level.

\begin{tabular}{|c|c|c|c|c|c|}
\hline \multirow{2}{*}{$N r}$. & \multirow{2}{*}{ Size } & \multirow{2}{*}{$\begin{array}{l}\text { Level } \\
\text { Code }\end{array}$} & $\operatorname{Max}$ & Averaos & Minimal \\
\hline & & & 1 & 0 & -1 \\
\hline 1. & $v(\mathrm{~m} / \mathrm{min})$ & $X_{I}$ & 120.89 & 86.35 & 51.81 \\
\hline 2. & $f(\mathrm{~mm} / \mathrm{rev})$ & $X_{2}$ & 0.10 & 0.085 & 0.055 \\
\hline 3. & $a(\mathrm{~mm})$ & $X_{3}$ & 1.5 & 1.0 & 0.5 \\
\hline
\end{tabular}

3. Selection of Turning Machine - The Sample is used in the turning machine V-Turn 410, production of German firm KNUTH.

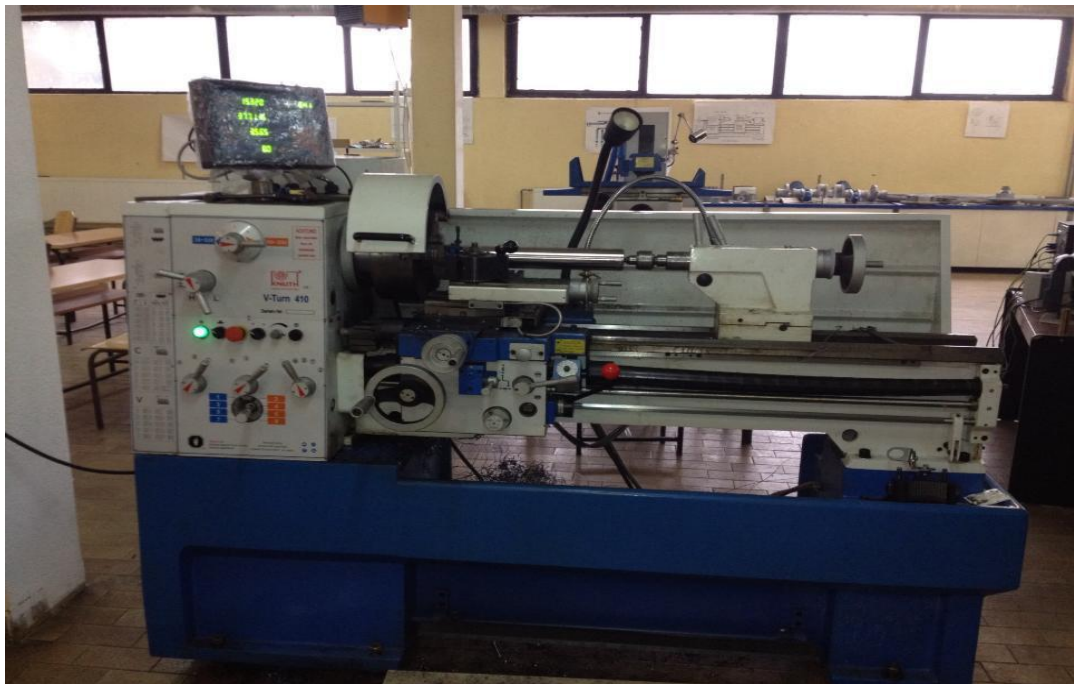

Fig 6. The machine by which the sample preparation was done.

4. Election of metering device - Measurement of the roughness surface parameters which is done in an computer device for measuring roughness TALYSURF INTRA of firm TAYLOR HOBSON, and vibration measurement in the turning process is done by the Comarator device for vibration measurement.
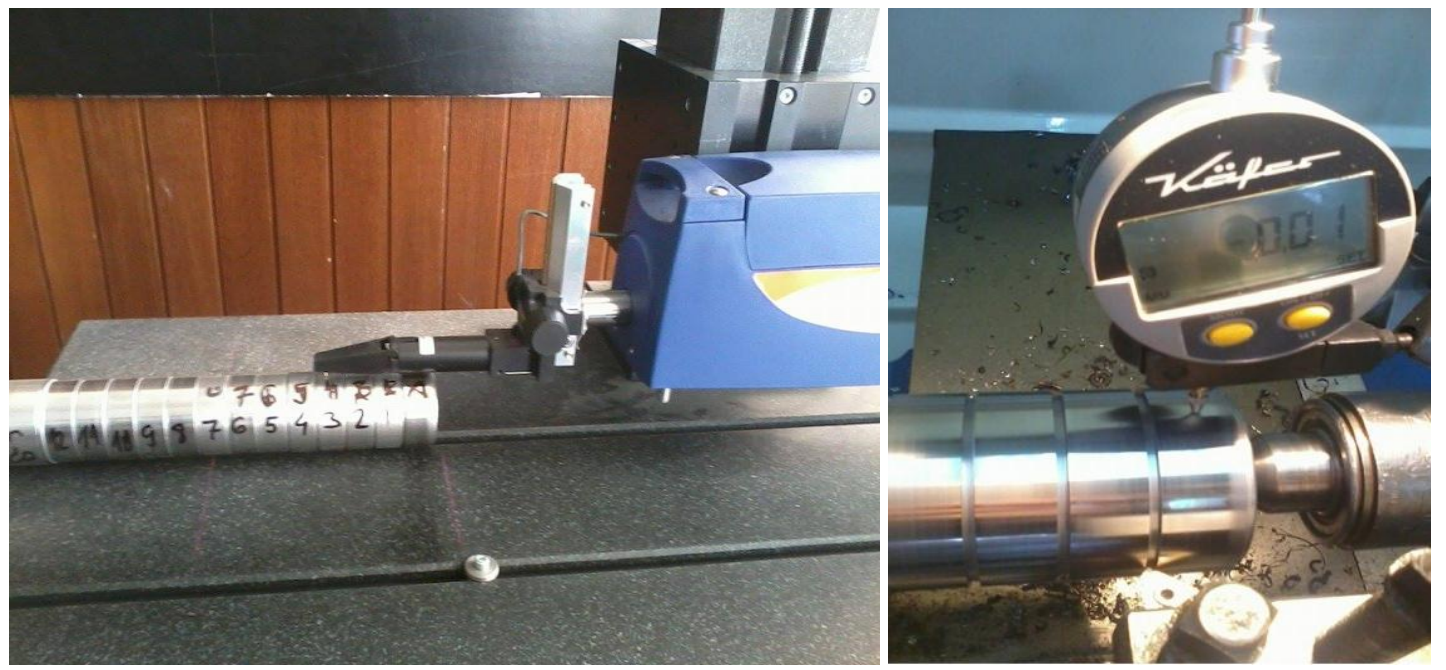

Fig. 7.The measuring device for measuring the roughness of processed surface TALYSURF-INTRA and the device of vibration measurement - Comperator 
The Vibration Impact On The Surface Roughness Which Are Made For Ck35 Steel During The...

\section{ACHIVED RESULTS}

For the sample preparation is used a three orthogonal factor with a point plan measurement and the repeating on point zero four times $\left(2^{3}+4\right)$.

Tab. 2. Matrix coded plan of the first row with three factors.

\begin{tabular}{|c|c|c|c|c|}
\hline \multirow[t]{2}{*}{$N r}$. & \multicolumn{4}{|c|}{ Level Kode } \\
\hline & $X_{0}$ & $X_{1}$ & $X_{2}$ & $X_{3}$ \\
\hline 1. & 1 & -1 & -1 & -1 \\
\hline 2. & 1 & 1 & -1 & -1 \\
\hline 3. & 1 & -1 & 1 & -1 \\
\hline 4. & 1 & 1 & 1 & -1 \\
\hline 5. & 1 & -1 & -1 & 1 \\
\hline 6. & 1 & 1 & -1 & 1 \\
\hline 7. & 1 & -1 & 1 & 1 \\
\hline 8. & 1 & 1 & 1 & 1 \\
\hline 9. & 1 & 0 & 0 & 0 \\
\hline 10. & 1 & 0 & 0 & 0 \\
\hline 11. & 1 & 0 & 0 & 0 \\
\hline 12. & 1 & 0 & 0 & 0 \\
\hline
\end{tabular}

Tab. 3. Measuring achived results during sample precessing by turning tool V-TURN

\begin{tabular}{|c|c|c|c|c|c|c|c|}
\hline \multirow{2}{*}{$\mathrm{Nr}$. } & \multicolumn{3}{|c|}{ Processing Regime } & \multirow{2}{*}{$\begin{array}{l}\text { Vibrations } \\
\mathrm{f}[\mathrm{Hz}]\end{array}$} & \multicolumn{3}{|c|}{ Surface Roughness } \\
\hline & $v(\mathrm{~m} / \mathrm{min})$ & $f(\mathrm{~mm} / \mathrm{rev})$ & $a(\mathrm{~mm})$ & & $R_{a}[\mu \mathrm{m}]$ & $R_{t}[\mu m]$ & $R_{z}[\mu m]$ \\
\hline 1. & 300 & 0.055 & 0.5 & 0.02 & 3.3087 & 26.9497 & 17.8739 \\
\hline 2. & 700 & 0.055 & 0.5 & 0.01 & 1.5787 & 19.2758 & 10.4920 \\
\hline 3. & 300 & 0.10 & 0.5 & 0.02 & 4.7309 & 33.5347 & 23.5675 \\
\hline 4. & 700 & 0.10 & 0.5 & 0.01 & 1.2528 & 11.8665 & 7.4757 \\
\hline 5. & 300 & 0.055 & 1.5 & 0.02 & 1.7843 & 21.1214 & 12.0449 \\
\hline 6. & 700 & 0.055 & 1.5 & 0.02 & 1.1860 & 12.7584 & 7.4307 \\
\hline 7. & 300 & 0.10 & 1.5 & 0.01 & 1.7084 & 15.0659 & 9.9310 \\
\hline 8. & 700 & 0.10 & 1.5 & 0.02 & 1.3892 & 20.0241 & 10.4640 \\
\hline 9. & 500 & 0.085 & 1.0 & 0.01 & 1.5954 & 15.6668 & 9.5878 \\
\hline 10. & 500 & 0.085 & 1.0 & 0.01 & 1.5198 & 22.3218 & 9.4953 \\
\hline 11. & 500 & 0.085 & 1.0 & 0.01 & 1.2641 & 10.2882 & 7.5643 \\
\hline 12. & 500 & 0.085 & 1.0 & 0.01 & 1.5103 & 19.3711 & 9.7873 \\
\hline
\end{tabular}

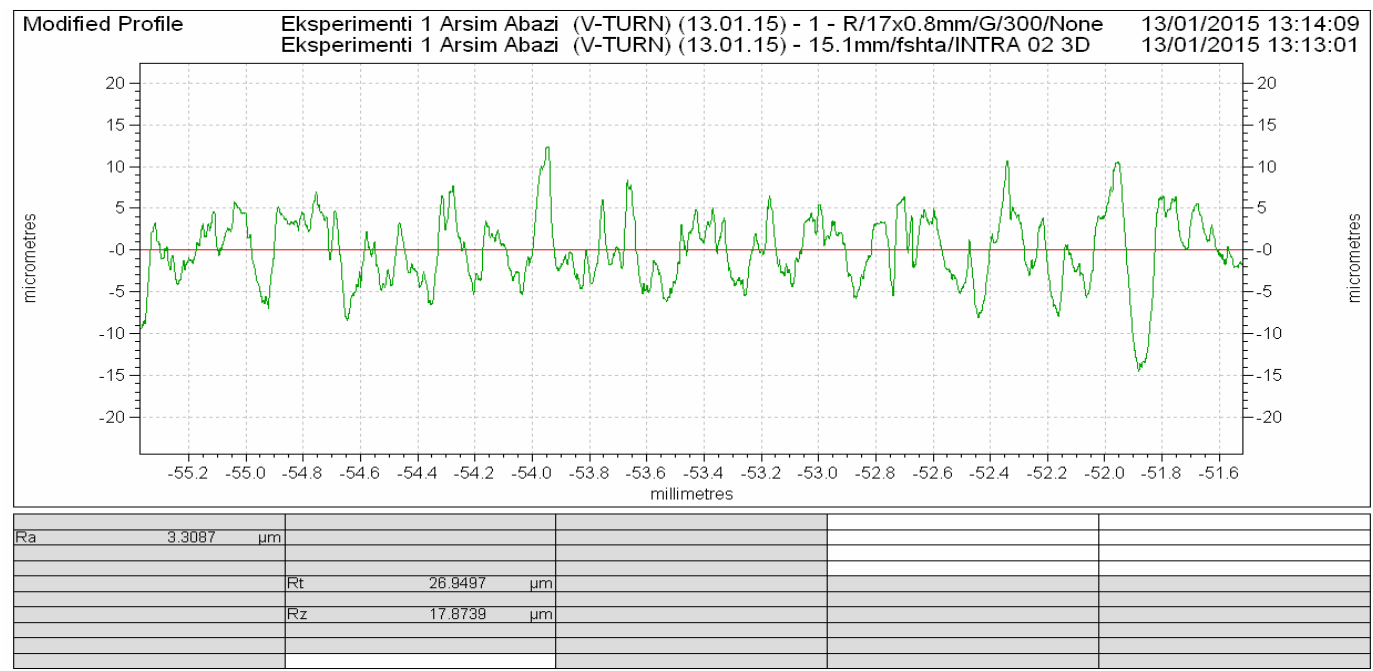

Fig. 8 Profilogram graphic interpretation for the first experiment

\section{ANALYSIS OF RESULTS}

Based on the achievement of metering results during the research vibration impact on surface severity for CK35 steel, it has been reflected the impact of the factors which have been used for the experiment implementation, such as cutting speed, cutting step and cutting depth.

Cutting speed-(v) has a great influence on vibration size and on the harshness of proceeded surface. The greater the velocity the less is the height of micro particles, which means that by increasing cutting speed decreases the processed surface harshness. During low-speed cutting ( $\mathrm{v}=300 \mathrm{~m} / \mathrm{min})$ obtained results show that we have got more harshness, and this happens due to increased vibrations, and the plastic deformations on the cutting area are larger. 
Cutting feet $(f)$ - The most influential factor on the vibration size and on the surface harshness is the cutting feet. The research shows that the increased in feet has influenced on increasing harshness. During processing on maximal feet $(f=0.10 \mathrm{~mm} / \mathrm{rev})$ have increased the severity of surfaces. This is because by increasing the cutting pace the cutting resistance grows, cutting temperature grows and this causes an increase in size of plastic deformation on the cutting area. During processing on low-speed $(f=0.055 \mathrm{~mm} / \mathrm{rev})$ the results have shown that by reducing the pace it also reduces the severity of the surface.

Cutting depth- The cutting depth, based on analysis results, related on cutting pace and cutting speed, is less influential on the severity of processed surface. By increasing depth $\left(\mathrm{a}_{\max }=1.5 \mathrm{~mm}\right)$, we have gained values with major parameters of the processed surfaces because by increasing the cutting depth, the cutting resistance increases, the cutting temperature and the deformations increase as well. While on the other hand, by reducing the cutting depth $\left(\mathrm{a}_{\min }=0.5 \mathrm{~mm}\right)$, the surface severity is reduced on the processed surface.

\section{V.}

\section{CONCLUSION}

Processed surface roughness depends on many factors, but for the research some factors have been adopted: cutting speed (v), cutting feet (f) and cutting depth (a). Physico-Chemical properties of material, altered structure through layers of processed surface and chip shape due to plastic deformation during the cutting process, geometry constant change of the cutting tool due to the wear, growth phenomenon and the appearance of the oxidation layers in the cutting edges, greatly affect the vibration and the processed surface. By this we conclude that the used factors in the experiment are just some of the indicators expressing their impact on vibrations and on the surface roughness. Considering the result analysis of obtained experimentally, during the research on vibration impact over processed surface harshness during the turning process for Ck35 steel according DIN standard, in the turning machine V-Turn, allows us obtaining scientific arguments which appear during the turning process.

\section{LITERATURE}

[1]. Msc. Arsim ABAZI “Ndikimi i vibrimeve në ashpërsinë e sipërfaqeve të punuara gjatë tornimit” Punim Masteri-Mitrovicë 2015.

[2]. Thomson, W. and Dahleh, M., 1998, Theory of Vibration with Application, 5th Ed., Prentice Hall, Upper Saddle River, NJ.

[3]. Weaver, Jr., W., Timoshenko, S., and Young, D., 1990, Vibration Problems in Engineering, 5th Ed., John Wiley and Sons, New York, NY.

[4]. Tony L.Schmitz, K. Scot Smith-"Machining Dynamics" NY 2009.

[5]. Dr. David Stephenson "METAL-CUTTING THEORY AND PRACTICE", University of Wisconsin-Madison, 2003. 